\title{
Successful endoscopic management of a large duodenal arteriovenous malformation using an over-the-scope clip
}

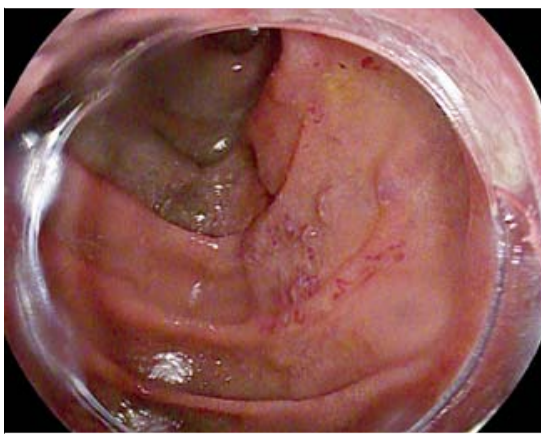

- Fig. 1 A large duodenal arteriovenous malformation in the second part of the duodenum.

A 24-year-old man was referred for further management of a large arteriovenous malformation (AVM) in the second part of his duodenum ( $\triangleright$ Fig. 1). He had a long history of refractory anemia requiring regular iron infusions and recurrent episodes of gastrointestinal bleeding necessitating hospital admission. Gastroscopy at his local hospital had shown a large duodenal AVM and computed tomography angiograms per-

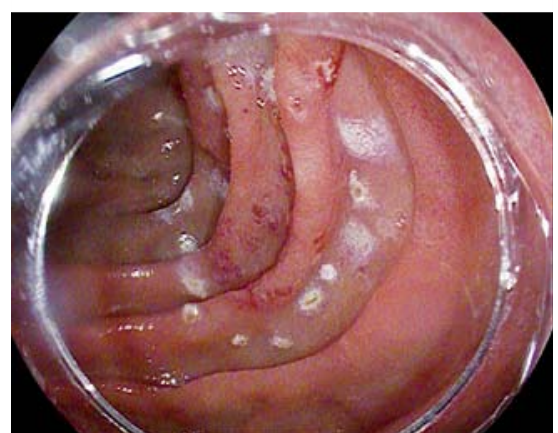

- Fig. 2 Application of argon plasma coagulation to mark the borders of the lesion.

formed during bleeding episodes failed to identify a vessel amenable to embolization. The patient was keen to avoid surgical resection and was referred for consideration of endoscopic management.

After discussion at our multidisciplinary team meeting, the option of an overthe-scope clip (OTSC) was considered most appropriate because it is minimally invasive and the lesion was endoscopi-

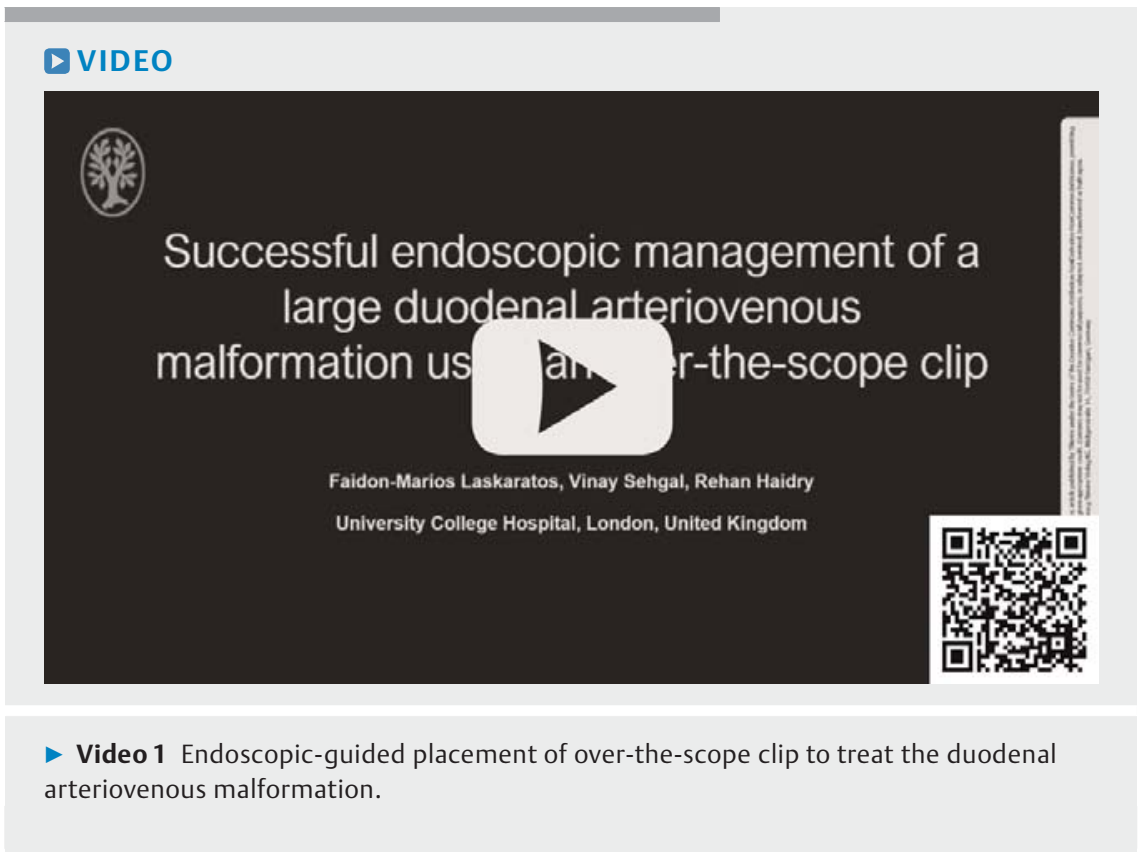




\section{Competing interests}

Dr. Haidry has received educational grants to support research infrastructure from Medtronic Ltd, Cook Endoscopy (fellowship support), Pentax Europe, C2 Therapeutics, Beamline Diagnostic, and Fractyl Ltd.

The authors

Faidon-Marios Laskaratos ${ }^{1,2}$, Vinay Sehgal ${ }^{1,3}$, Rehan Haidry ${ }^{1,3}$

1 Department of Gastroenterology, University College London Hospitals NHS Foundation Trust, London, United Kingdom

2 Institute for Liver and Digestive Health, University College London (UCL), London, United Kingdom

3 Division of Surgery and Interventional Science, University College London (UCL), London, United Kingdom

\section{Dr. Faidon-Marios Laskaratos MBBS MSC PhD MRCP(UK)}

Department of Gastroenterology, University College London Hospitals NHS Foundation Trust, London, United Kingdom

Fax: +44 2034567890

flaskaratos@gmail.com

\section{References}

[1] Mathew S, Zacharias P, Kumar L et al. Duodenal arteriovenous malformation: endosonographic diagnosis and coil embolization. Endoscopy 2016; 48: E378-E379

[2] Inouye P, Marcon N, Pugash R et al. Embolization of a duodenal arteriovenous malformation in hereditary hemorrhagic telangiectasia: case report and review of the literature. Can J Gastroenterol 2003; 17: 661 665

[3] Poon RT, Poon J. Massive GI bleeding due to a duodenal arteriovenous malformation. Gastrointest Endosc 2000; 52: 101-104

\section{Bibliography}

Endosc Int Open 2021; 09: E909-E910

DOI 10.1055/a-1399-8589

ISSN 2364-3722

(c) 2021. The Author(s).

This is an open access article published by Thieme under the terms of the Creative Commons Attribution-NonDerivativeNonCommercial License, permitting copying and reproduction so long as the original work is given appropriate credit. Contents may not be used for commercial purposes, or adapted, remixed, transformed or built upon. (https:// creativecommons.org/licenses/by-nc-nd/4.0/)

Georg Thieme Verlag KG, Rüdigerstraße 14, 70469 Stuttgart, Germany

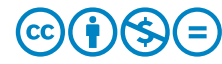

